\title{
INFLUÊNCIA DO ETILENO SOBRE CARACTERÍSTICAS QUIMMICAS DE FRUTOS DE MANGA VAR. KEITT, COLHIDOS EM ESTÁDIO PRÉ-CLIMATÉRICO
}

\author{
R.C.C. CONEGLIAN; J.D. RODRIGUES \\ Depto. de Botânica - Instituto de Biociências/UNESP - CEP: 18618-000 - Botucatu,SP
}

\begin{abstract}
RESUMO: Frutos de manga (Mangifera indica L.) variedade Keitt, colhidos em estádio pré-climatérico, receberam tratamento com 500 e 1.000 ppm de Ethrel (com exceção da testemunha), sendo submetidos a determinações de carboidratos solúveis, vitamina $C$, proteínas e umidade, de acordo com amostragens realizadas 3, 6, 9 e 16 dias pós-colheita. Os resultados obtidos, revelaram que o Ethrel não excerceu nenhuma influência nas características químicas dos frutos e que, somente em termos de carboidratos solúveis e vitamina $\mathbf{C}$, os frutos mostraram alterações durante a maturação.
\end{abstract}

Descritores: manga, Ethrel, maturaçāo, pós-colheita

\section{INFLUENCE OF ETYLEN ON THE CHEMICAL CHARACTERISTICS OF MANGO FRUITS VAR. KEITT, HARVESTED IN THE PRE-CLIMATERIC STAGE}

\begin{abstract}
Mango fruits (Mangifera indica L.) Keitt variety, harvested in the pre-climateric stage were treated with 500 and $1,000 \mathrm{ppm}$ of Ethrel (except the control). Soluble carbohydrates, vitamin C, proteins and humidity were evaluated on the samples at 3, 6,9 and 16 days post-harvest. The results obtained, showed that Ethrel did not have influence on the chemical characteristics of the fruits. Fruits showed modifications during the maturation only for the parameters of soluble carbohydrate and vitamin $C$.
\end{abstract}

Key Words: mango, Ethrel, maturation, post-harvest.

\section{INTRODUÇÃO}

A manga é uma fruta tropical muito importante, pertencendo todas as variedades comerciais à espécie Mangifera indica L. Seu cultivo tem sido difundido por todas as regiões tropicais e subtropicais do mundo, sendo a Índia, o maior produtor com mais de 9 bilhões de toneladas em 1991. O Brasil também se coloca entre os grandes produtores mundiais dessa fruta, com 395 milhões de toneladas no mesmo ano, segundo boletins da FAO (1992). Em nosso país, a mangueira é cultivada em quase todas as regiões, sendo que ainda pode expandir muito a sua produção através do aumento de áreas plantadas, além de redobrar a atenção na melhoria da qualidade do produto. No Brasil, onde a predominância é de variedades americanas ou oriundas destas, os frutos amadurecem de novembro a março, e a maturação desuniforme destes em uma mesma planta, exige colheita escalonada que pode prolongar-se por até um mês (MARANCA, 1986). Existem ainda muitas controvérsias, na determinação do momento exato da colheita. De acordo com MANICA (1981), esta seria observada empiricamente pela mudança de cor da casca, época do ano ou através da determinação do conteúdo ácido e de açúcar dos frutos.

BLEINROTH (1988), descreve a densidade como um fator consistente, na determinação do ponto de colheita. Outros autores ainda asseguram que um dos melhores parâmetros de maturação seria a firmeza da polpa, que começa a diminuir no ponto de colheita. Porém, os métodos visuais são os mais utilizados pelos produtores, baseando-se na mudança de coloração da casca, tamanho e formato do fruto, que geralmente passa de arredondado para elíptico.

De acordo com BLEINROTH (1988), citado anteriormente, esse desenrolar natural da maturação pode ser acelerado através da aplicação exógena de etileno. Em frutos climatéricos, como a manga, esse hormônio antecipa significativamente - período de tempo requerido para o pico climatérico, principalmente quando aplicado antes dessa fase. Várias substâncias são capazes de liberar etileno nos tecidos vegetais, e destas a mais 
utilizada e efetiva é o ácido 2-cloroétil-fosfônico, conhecido comercialmente como Ethrel, Ethephon ou CEPA.

Dessa forma, o objetivo deste trabalho foi de avaliar a atuação do etileno na maturação de frutos de manga, colhidos 7 dias antes do período normal, verificando se o etileno aplicado exogenamente, altera a composição química das mangas.

\section{MATERIAL E MÉTODOS}

Foram utilizados frutos de manga, retirados de um pomar comercial no município de Lins,SP. Os mesmos, pertencentes à variedade Keitt, foram colhidos em estágio pré-climatérico (correspondendo a cerca de 170 dias após o início da formação desses frutos). Esta variedade carateriza-se por produzir frutos grandes (cerca de $12 \mathrm{~cm}$ de comprimento), de forma ovalada, polpa sucosa e sem fibras e casca de coloração amarelo-esverdeada com laivos vermelhos. Foi mantida a regularidade em termos de tamanho, coloração e grau de maturação, sendo todos eles retirados de uma área onde as matrizes tinham cerca de 8 anos.

Após a colheita as mangas, com exceção da testemunha, foram submetidas aos tratamentos com 500 e 1.000 ppm de Ethrel (ácido 2-cloroetil-fosfônico), que segundo BLEINROTH (1981), é o produto mais efetivo em liberar etileno no tecido vegetal. Os tratamentos deram-se através de imersão dos frutos em solução por 5 minutos. Cada tratamento teve 3 repetições, sendo cada uma delas composta por 14 frutos que iam sendo amostrados (dois a dois) aleatoriamente, de $3 \mathrm{em} 3$ dias (com exceção da última amostragem que teve um intervalo de 7 dias), a partir da data dos tratamentos até que a completa maturação se processasse.

Cada amostra foi analisada para a determinação de carboidratos solúveis (método descrito por JOHNSON et al., 1966), vitamina C (método colorimétrico de Tillmans, descrito por WINTON \& WINTON, 1958), teor de proteínas, através da obtenção do $\mathrm{N}$-total por digestão sulfúrica (ASSOCIATION OF OFFICIAL ANAL YTICAL CHEMISTS, 1970) e porcentagem de umidade [relação peso úmido/peso seco $\mathrm{em}$ estufa a $100^{\circ} \mathrm{C}$, com circulação de ar forçada (ASSOCIATION OF OFFICIAL ANALYTICAL CHEMISTS, 1970)]. Obtidos os resultados, fez-se a análise de variância, sendo as médias comparadas pelo teste de Tukey, segundo especificações de GOMES (1981), utilizando-se o nivel de $5 \%$ de significância.

\section{RESULTADOS E DISCUSSÃO}

Carboidratos solúveis: A TABELA 1 contém os resultados das determinações de carboidratos solúveis, obtidos em cada uma das amostragens efetuadas.

A análise estatística revela que existe diferença significativa somente em termos de amostragens, podendo os tratamentos serem considerados semelhantes, apesar da dosagem de $1.000 \mathrm{ppm}$ de Ethrel mostrar-se biologicamente superior.

No caso dos carboidratos solúveis, apesar da semelhança estatística, o comportamento de cada um dos 3 tratamentos (testemunha, $500 \mathrm{e}$ $1.000 \mathrm{ppm}$ de Ethrel) foi distinto: a testemunha mostrou incremento da primeira para a segunda amostragem e da terceira para a última, conferindo oscilação nos níveis durante o processo de maturação. Já o tratamento de 500 ppm de Ethrel, apresentou acréscimo nas três primeiras amostragens e redução somente na quarta. E finalmente, só o de $1.000 \mathrm{ppm}$ teve aumento da primeira até a quarta amostragem, coincidindo com citações de BLEINROTH (1988), onde o autor refere que além da diminuição do amido, outras mudanças podem ser observadas em frutos tropicais durante o processo de maturação. Entre elas, a redução de firmeza, devido ao amolecimento, causado pela solubilização crescente de protopectinas, que se constituem de formas menos solúveis de carboidratos, originando formas mais solúveis, como por exemplo pectinas ou ácidos pécticos. Assim, essas protopectinas formariam polímeros com menor número de grupos metoxílicos, que tornariam o fruto menos firme. Desse modo, as enzimas responsáveis pela degradação das protopectinas, seriam encontradas em níveis mais elevados no fruto maduro havendo, portanto, condições propicias ao incremento de carboidratos nas formas mais solúveis.

Os diferentes comportamentos da testemunha e do tratamento com $500 \mathrm{ppm}$, poderiam ser baseadas na menor eficiência do etileno quando aplicado em concentração mais baixa (ou quando não aplicado exogenamente). MEDINA (1981), também se refere às enzimas degradadoras de pectina, poligalacturonase e pectinesterase, como as mais comumente 
TABELA 1 - Carboidratos Solúveis.

A: Análise de Variância dos resultados obtidos para carboidratos solúveis, expressos em $\mathrm{g} / 100 \mathrm{~g}$ de amostra

\begin{tabular}{lccc}
\hline Causa da Variação & GL & QM & F \\
\hline Blocos & 2 & 13,8702 & 1,99 \\
Tratamentos & 2 & 5,4004 & 0,77 \\
Amostragens & 3 & 93,8009 & $13,48 *$ \\
Interação T x A & 6 & 7,9536 & 1,14 \\
Resíduo & 22 & 6,9551 & \\
\hline TOTAL & 35 & \\
\hline \hline
\end{tabular}

$\mathrm{cv}=29,07 \%$

B: Médias dos resultados obtidos para carboidratos solúveis, expressos em $\mathbf{g} / 100 \mathrm{~g}$ de amostra.

\begin{tabular}{|c|c|c|c|c|c|}
\hline \multirow[b]{2}{*}{ Tratamentos } & \multicolumn{4}{|c|}{ Amostragens (Dias pós-tratamento) } & \multirow[b]{2}{*}{$\begin{array}{c}\text { Médias } \\
\text { Gerais }\end{array}$} \\
\hline & 3 & 6 & 9 & 16 & \\
\hline Testemunha & 5,22 & 8,37 & 7,94 & 11,96 & 8,37 \\
\hline 500 & 4,56 & 8,54 & 12,72 & 10,63 & 9,11 \\
\hline 1000 & 4,18 & 9,96 & 10,66 & 14,05 & 9,71 \\
\hline \multirow[t]{2}{*}{ Médias gerais das amostragens } & 4,65 & 8,95 & 10,44 & 12,21 & - \\
\hline & Tratamentos & Amostragens & \multicolumn{3}{|c|}{ Interação $T \times A$} \\
\hline d.m.s. $5 \%$ & - & 3,45 & & - & \\
\hline
\end{tabular}

encontradas nos frutos, quando estes avançam no processo de amadurecimento. Assim, se a concentração de Ethrel utilizada não foi suficiente para interferir nesse processo, logicamente o aumento no nível de carboidratos solúveis será menos eficiente, originando oscilações durante a maturação, além de proporcionar um menor teor no final desta.

Vitamina C: Em termos de vitamina C, os dados obtidos estão expressos na TABELA 2. Nota-se pela TABELA 2-A, da análise de variância, que estatisticamente, somente as amostragens são diferentes, havendo semelhança entre os tratamentos.

De acordo com SHAMUGAVELU et al. (1976), tratamento com etileno reduz o conteúdo de vitamina $\mathbf{C}$ de mangas e abacates, quando expostas a 10.000 e 4.000 ppm desse hormônio, respectivamente. Este fato, de certo modo, retrata o comportamento dos 3 tratamentos a que os frutos de manga foram submetidos. 
TABELA 2 - Vitamina C.

A: Análise de Variância dos resultados obtidos para vitamina C, expressos em $\mathrm{g} / 100 \mathrm{~g}$ de amostra

\begin{tabular}{lccc}
\hline \hline Causa da Variação & GL & QM & F \\
\hline Blocos & 2 & 0,8042 & 0,048 \\
Tratamentos & 2 & 5,8037 & 0,35 \\
Amostragens & 3 & 700,5305 & $42,67 *$ \\
Interação T x A & 6 & 6,3245 & 0,38 \\
Resíduo & 22 & 16,4153 & \\
TOTAL & 35 & & \\
\hline \hline
\end{tabular}

$\mathrm{cv}=21,32 \%$

B: Médias dos resultados obtidos para vitamina C, expressos em $\mathrm{g} / 100 \mathrm{~g}$ de amostra.

\begin{tabular}{ccccccc}
\hline \multicolumn{7}{c}{ Amostragens (Dias pós-tratamento) } \\
\hline Tratamentos & 3 & 6 & 9 & 16 & $\begin{array}{c}\text { Médias } \\
\text { Gerais }\end{array}$ \\
\hline Testemunha & 27,47 & 27,18 & 10,34 & 11,83 & 19,20 \\
500 & 28,17 & 26,58 & 11,44 & 12,08 & 19,56 \\
1000 & 27,89 & 22,23 & 11,74 & 11,03 & 18,22 \\
Médias gerais das amostragens & 27,84 & 25,33 & 11,17 & 11,64 & - \\
\hline & Tratamentos & Amostragens & & Interação T X A \\
\hline d.m.s. 5\% & - & 5,30 & & - & \\
\hline \hline
\end{tabular}

Através da TABELA 2-B, percebe-se que realmente houve um decréscimo acentuado no teor de ácido ascórbico, conforme se caminha da primeira para a terceira amostragem, com um pequeno aumento no final, no caso da testemunha e do tratamento de $500 \mathrm{ppm}$; o de $1.000 \mathrm{ppm}$ continuou decrescendo. Apesar dessas pequenas diferenças, pode-se concluir que o período de 3 dias, compreendido entre a segunda e terceira amostragens, foi decisivo em termos de vitamina C, já que aí ocorreu redução de seus níveis para menos da metade do conteúdo inicial, mantendo-se relativamente constante a partir da terceira amostragem, onde o fruto estava quase maduro; o tratamento com $1.000 \mathrm{ppm}$ de Ethrel, apesar de possuir no início, um índice elevado de vitamina $C$, apresentou no final, o nível mais baixo, indicando que, apesar de não ser estatisticamente diferente, este tratamento facilitou ou provocou, de certa forma, a queda da vitamina $C$, o que não é ideal do ponto de vista nutricional, apesar dessa queda correr normalmente nos frutos, quando estes se aproximam da maturação (BLEINROTH, 1981).

Protef́nas: Os resultados obtidos para proteínas são apresentados na TABELA 3. A análise da TABELA 3-B, permite observar uma certa tendência de acréscimo no teor de proteínas, conforme o fruto se aproxima da maturidade. Porém, as diferentes intensidades com que esses ocorreram nas várias amostragens e tratamentos, não foram suficientes para se constatar diferenças estatísticas. Percebe-se, que apesar de não significativo, o tratamento com $1.000 \mathrm{ppm}$ de Ethrel, propiciou melhor resultado médio em termos protéicos, em relação aos demais tratamentos. 
TABELA 3 - Proteínas.

A: Análise de Variância dos resultados obtidos para proteínas, expressos em g/100g de amostra

\begin{tabular}{lccc}
\hline \hline Causa da Variação & GL & QM & F \\
\hline Blocos & 2 & 0,0372 & 0,15 \\
Tratamentos & 2 & 0,2990 & 1,24 \\
Amostragens & 3 & 0,6090 & 2,54 \\
Interação T x A & 6 & 0,1207 & 0,50 \\
Resíduo & 22 & 0,2392 & \\
\hline TOTAL & 35 & & \\
\hline \hline cv $=24,34 \%$ & &
\end{tabular}

B: Médias dos resultados obtidos para proteínas, expressos em g/100g de amostra.

\begin{tabular}{cccccc}
\hline \hline \multicolumn{7}{c}{ Amostragens (Dias pós-tratamento) } \\
\hline Tratamentos & 3 & 6 & 9 & 16 & $\begin{array}{c}\text { Médias } \\
\text { Gerais }\end{array}$ \\
\hline Testemunha & 1,59 & 1,83 & 2,48 & 2,05 & 1,98 \\
500 & 1,44 & 1,75 & 2,00 & 2,24 & 1,85 \\
1000 & 2,01 & 2,16 & 2,15 & 2,37 & 2,17 \\
Médias gerais das amostragens & 1,68 & 1,91 & 2,21 & 2,22 & - \\
\hline \hline
\end{tabular}

Essas constatações, concordam com BLEINROTH (1981) que indica que o aumento de proteínas, no período de maturação do fruto, pode ser atribuído ao fato da metionina e/ou a beta-alanina, atuar como precursor do etileno em tecidos vegetais. Portanto, se o etileno é produzido na fase de amadurecimento, torna-se indispensável que os níveis desses aminoácidos aumentem, para que este hormônio possa ser sintetizado, havendo consequentemente, acréscimo no teor de proteínas do fruto.

MATOO (1969) e PANTÁSTICO et al. (1975), confirmam esses fatos ressaltando, porém, ser a banana, uma exceção, já que há degradaçãa de proteínas quando faz-se tratamento préclimatérico com etileno.
Umidade: Os resultados referentes a este parâmetro, encontram-se na TABELA 4. Também aqui, não foi verificado nenhuma diferença estatisticamente considerável, tanto $\mathrm{em}$ termos de tratamentos, como de amostragens. É nitidamente visível pela TABELA 4-B, que a taxa de umidade sofreu um crescente aumento, da primeira para a quarta amostragem, nos 3 tratamentos (com exceção da terceira amostragem do tratamento com $1.000 \mathrm{ppm}$ de Ethrel, na qual houve queda). Tal fato pode, possivelmente, ser explicado pela entrada de água por difusão, ocasionada pela imersão dos frutos tratados na solução de fitohormônio, levando-os a sofrerem aumentos na umidade. Além disso, a alta umidade relativa, apresentada pela atmosfera, no período de 
TABELA 4 - Umidade.

A: Análise de Variância dos resultados obtidos para umidade, expressos em porcentagem.

\begin{tabular}{lccc}
\hline \hline Causa da Variação & GL & QM & F \\
\hline Blocos & 2 & 4,1477 & 1,24 \\
Tratamentos & 2 & 3,1214 & 0,93 \\
Amostragens & 3 & 5,2855 & 1,58 \\
Interação T x A & 6 & 0,6747 & 0,20 \\
Resíduo & 22 & 3,3326 & \\
\hline TOTAL & 35 & & \\
\hline \hline
\end{tabular}

$\mathrm{cv}=2,18 \%$

B: Médias dos resultados obtidos para umidade, expressos em porcentagem.

\begin{tabular}{|c|c|c|c|c|c|}
\hline \multirow[b]{2}{*}{ Tratamentos } & \multicolumn{4}{|c|}{ Amostragens (Dias pós-tratamento) } & \multirow[b]{2}{*}{$\begin{array}{l}\text { Médias } \\
\text { Gerais }\end{array}$} \\
\hline & 3 & 6 & 9 & 16 & \\
\hline Testemunha & 81,63 & 82,50 & 82,93 & 84,48 & 82,88 \\
\hline 500 & 83,11 & 83,75 & 83,99 & 84,77 & 83,90 \\
\hline 1000 & 83,36 & 83,12 & 82,92 & 84,21 & 83,40 \\
\hline Médias gerais das amostragens & 82,70 & 83,12 & 83,28 & 84,48 & - \\
\hline
\end{tabular}

realização das amostragens (64 a 70\% de U.R.), permitiu que os frutos incorporassem umidade (já que não foram armazenados em nenhum local com controle de umidade), levando ao aumento nas taxas desse parâmetro, o que não seria esperado em condições de dias mais secos. O comportamento habitual dos frutos, em relação ao teor de umidade é citado por BLEINROTH (1981), que preconiza achar-se a água acumulada em maiores proporções no fruto verde, $e$, conforme este vai amadurecendo, o nível tende a decrescer devido à transpiração, que é mais intensa nesse período.

\section{CONCLUSÃO}

A aplicação exógena de etileno (na forma de Ethrel a 500 e 1.000 ppm), não afetou as características químicas dos frutos de manga.

Em termos do processo de maturação, somente para o conteúdo de carboidratos solúveis e de vitamina $\mathrm{C}$, houve efeito dos tratamentos utilizados.

Para proteínas e umidade, não houve alteração significativa durante todo o desenrolar da maturação. 


\section{REFERENCIAS BIBLIOGRAFICAS}

ASSOCIATION OF OFFICIAL ANALYTICAL CHEMISTS. Official methods of anlysis. 11.ed. Washington, 1970. 1015p.

BLEINROTH, E.W. Determinação do ponto de colheita das frutas. In: INSTITUTO DE TECNOLOGIA DE ALIMENTOS. Tecnologia de pós-colheita de frutas tropicais. Campinas: ITAL, 1988. cap.1, p.1-17.

BLEINROTH, E.W. Matéria prima. In: INSTITUTO DE TECNOLOGIA DE ALIMENTOS. Manga: da cultura ao processamento e comercialização. São Paulo: ITAL, 1981. cap.2, p.243-287. (Frutas tropicais, 8).

FOOD QUARTELY BULLETIN OF STATISTICS. Rome, v.5, p.2-3, 1992.

GOMES, F.P. Curso de estatística experimental. 9.ed. São Paulo: Nobel, 1981. 430p.

JOHNSON, R.R.; BALWANII, T.L.; MCLUB, K.E.; DEHORRITY, B.A. Corn plant maturity. II. Effect on "in vitro" cellulose digestibility and soluble carbohydrate content. Journal of the American Society of Agronomy, Madison, v.25, p.617-623, $19 \kappa 6$.

MANICA, I. Fruticultura tropical: manga. São Paulo: Agronômica Ceres, 1981. 135p.
MARANCA, G. Fruticultura comercial; manga e abacate. 6.ed. São Paulo: Nobel, 1986. 138p.

MATOO, A.K. Biochemical aspects of ripening and chilling injury in mango fruit. Fruits, Paris, v.1, p.111, 1969.

MEDINA, I.C. Cultura. In: INSTITUTO DE TECNOLOGIA DE ALIMENTOS. Manga: da cultura ao processamento e comercialização. São Paulo: ITAL, 1981. cap.1, p.9-227. (Frutas tropicais, 8).

PANTASTICO, E.B.; MATOO, A.K.; PHAN, C.T. Ethylene action on ripening. In: PANTASTICO, E.B. Postharvest physiology, handling and utilization of tropical and subtropical fruits and vegetables. Connecticut: AVI Publishing, 1975. cap.5, p.75-85.

SHAMUGAVELU, K.G.; SELVARAJIP, P.; VEEDANNAH, L.; CHITTARAUCHELVAN, R. Effect of ethephon on the ripening of fruits. Progressive Horticulture, Uttar Pradesh, v.8, p.89-96, 1976.

WINTON, A.L.; WINTON, K.B. Análises de alimentos. Barcelona: Hispano Americana, 1958. 205p.

Enviado para publicação em 28.05 .93

Aceito para publicação em 16.08 .93 